ARTICLE

https://doi.org/10.1038/s41467-019-10842-5

\title{
An inter-model assessment of the role of direct air capture in deep mitigation pathways
}

Giulia Realmonte1, Laurent Drouet (10 1, Ajay Gambhir², James Glynn (D) ${ }^{3}$, Adam Hawkes², Alexandre C. Köberle ${ }^{2}$ \& Massimo Tavoni (1) 1,4

The feasibility of large-scale biological $\mathrm{CO}_{2}$ removal to achieve stringent climate targets remains unclear. Direct Air Carbon Capture and Storage (DACCS) offers an alternative negative emissions technology (NET) option. Here we conduct the first inter-model comparison on the role of DACCS in 1.5 and $2{ }^{\circ} \mathrm{C}$ scenarios, under a variety of techno-economic assumptions. Deploying DACCS significantly reduces mitigation costs, and it complements rather than substitutes other NETs. The key factor limiting DACCS deployment is the rate at which it can be scaled up. Our scenarios' average DACCS scale-up rates of $1.5 \mathrm{GtCO}_{2} / \mathrm{yr}$ would require considerable sorbent production and up to $300 \mathrm{EJ} / \mathrm{yr}$ of energy input by 2100 . The risk of assuming that DACCS can be deployed at scale, and finding it to be subsequently unavailable, leads to a global temperature overshoot of up to $0.8^{\circ} \mathrm{C}$. DACCS should therefore be developed and deployed alongside, rather than instead of, other mitigation options.

\footnotetext{
${ }^{1}$ RFF-CMCC European Institute on Economics and the Environment (EIEE), Centro Euro-Mediterraneo sui Cambiamenti Climatici, Milan 20144, Italy. ${ }^{2}$ Imperial College London, Grantham Institute, London SW7 2AZ, UK. ${ }^{3}$ MaREI Centre, Environmental Research Institute, University College Cork, Cork T23 XE10, Ireland. ${ }^{4}$ Department of Management, Economics and Industrial Engineering, Politecnico di Milano, Milan 20156, Italy. Correspondence and requests for materials should be addressed to G.R. (email: giulia.realmonte1@gmail.com)
} 
T he Paris Agreement has set ambitious objectives to keep global warming well below $2{ }^{\circ} \mathrm{C}$, and the scientific debate has recently focused on the pursuit of $1.5^{\circ} \mathrm{C}$ targets ${ }^{1}$. Given the current level of $\mathrm{CO}_{2}$ emissions approaching $40 \mathrm{GtCO}_{2} / \mathrm{year}^{2}$ and the delay of global mitigation efforts, large-scale removal of $\mathrm{CO}_{2}$ from the atmosphere will likely be needed. Studies on Negative Emission Technologies (NETs), also referred to as Carbon Dioxide Removal (CDR), have been conducted for almost two decades, but the topic has received more attention since the IPCC's Fifth Assessment Report (AR5) published in 2013 ${ }^{3}$.

Bioenergy with Carbon Capture and Storage (BECCS) and afforestation are considered the most likely options to realise negative emissions, and have been largely investigated in many Integrated Assessment Modeling (IAM) studies. However, concerns about the sustainability of biological strategies and competition with food, water use, and ecosystems $s^{4,5}$ have led to a focus on alternatives to sequester carbon from the atmosphere. Direct Air Carbon Capture and Storage (DACCS) is a complementary technology; it can capture the $\mathrm{CO}_{2}$ produced by distributed sources, is modular and does not have major water and land interactions ${ }^{5-7}$, while competing for geological storage with other carbon sequestration options. To date, only a few modeling exercises have included CDR measures other than afforestation and BECCS, and never in an inter-model comparison $^{8-10}$.

DACCS captures $\mathrm{CO}_{2}$ from ambient air and subsequently stores it. Despite being at an early stage of development, it is gaining increasing attention, with multiple companies developing designs at a commercial scale ${ }^{11-13}$. Compared to other sequestration options, capturing $\mathrm{CO}_{2}$ directly from the air presents a number of advantages. Like other NETs, it can address distributed emissions, such as those from transport, aviation and intensive industrial sectors, together accounting for almost $50 \%$ of total emissions ${ }^{14}$. Designs for DACCS plants are diverse, some of them being modular, which extends a prospect of more rapid scaling ${ }^{15}$. Most demand little land, although some might still require significant although reduced water inputs $s^{5,16}$. Their main drawback is the low concentration of carbon dioxide in ambient air, meaning that a large amount of energy input is required.

Two groups of technologies can be identified as most promising, from a technical and economic perspective. The first (hereafter named as DAC1) is based on using water solutions containing hydroxide sorbents with a strong affinity for $\mathrm{CO}_{2}$, such as sodium hydroxide, calcium hydroxide and potassium hydroxide $^{6,17-20}$. The second (DAC2) uses amine materials bonded to a porous solid support ${ }^{12,21-23}$. A wider range of solid sorbents are being investigated (e.g. ionic membranes ${ }^{24}$, zeo$\operatorname{lites}^{25}$, solid oxides ${ }^{26}$ ), but were not included in our analysis as they are still at the research stage. Hydroxide solutions require high-temperature heat to be regenerated $\left(T>800^{\circ} \mathrm{C}\right)$, which can be provided by burning natural gas, while amine adsorbents require only approximately $85-120^{\circ} \mathrm{C}$, meaning that waste heat can be used. While DAC1 is based on large scale plants, capturing $1 \mathrm{MtCO}_{2} /$ year, DAC2 has a modular design, that might be suitable for mass production and potentially rapid cost reduction (see Methods). DAC1 technology is more mature. It employs equipment already developed and adopted in other sectors (e.g. pulp and paper industry): the major expenditure is related to capital investment for building plant facilities, with limited potential for future cost reduction. Conversely, for DAC2 the potential for design and cost improvement is arguably higher, but issues regarding sorbent degradation may lead to high operational expenditure. Currently there is huge uncertainty on DACCS economics, with estimates in the literature ranging from 100 to $1000 \$ / \mathrm{tCO}_{2}{ }^{7}$, according to the different designs proposed and the purity level of the captured $\mathrm{CO}_{2} /$ year $^{27}$.
This paper investigates the role of DACCS as part of a diversified portfolio of mitigation strategies, so as to inform policymakers about its potential in low stabilization scenarios. We incorporate detailed technical and economic characteristics of a range of DACCS technologies into two IAMs, using the latest available estimates from the literature ${ }^{17}$. Considering the large degree of uncertainty around this new technology, besides parametric sensitivity analysis, we implement a model comparison adopting two complementary IAMs: a bottom-up technology rich model (TIAM-Grantham) and a hybrid, economy-climate model (WITCH). We also explore the requirements in terms of resource use and the consequences of DACCS failure on global temperature.

Results suggest that DACCS allows an easing of near term mitigation, and can significantly reduce climate policy costs. DACCS complements, rather than substitutes other negative emission technologies. The key factor governing the role of DACCS compared to other mitigation and negative emissions strategies is the rate at which DACCS capacity can be ramped up. Such a massive deployment requires a major refocusing of the manufacturing and chemical industries for sorbent production, and a large need for electricity and heat. Assuming that DACCS can be deployed at scale, and finding it to be subsequently unavailable, leads to a global temperature overshoot of up to $0.8^{\circ} \mathrm{C}$. Our results therefore show the considerable potential of DACCS but also highlight a large number of challenges which commend caution and further scrutiny.

\section{Results}

Modeling DACCS within integrated assessment models. Compared to previous studies including DACCS in $\mathrm{IAMs}^{8-10,16}$, we distinguish among different technology options, namely DAC1 and DAC2 as described above. We include the use of waste heat to operate the amine-based plants, recovering it from energy-intensive industries and renewable power plants. In order to define energy inputs and cost assumptions, we combine data from the available literature with estimates from the companies operating the first demonstration plants. Given the large uncertainty, we specify scenarios which have high and low levels of the key techno-economic parameters (see Table 1-3). Technology representation is further discussed in Methods.

We use two different IAMs, TIAM-Grantham, and WITCH. TIAM-Grantham is a bottom-up energy system model, with a detailed representation of technologies across sectors. WITCH combines a bottom-up energy sector description with a top-down macro-economic approach. Detailed information about both models can be found in Supplementary Notes 1-3.

According to the different model features, in TIAM-Grantham we have implemented both DACCS technologies, and explicit characterization of the recovery of waste heat, while in WITCH we have only included DAC1, fuelled by natural gas. We harmonize a range of input assumptions, which are later shown to be critical in determining model outcomes, regarding technology take-up levels and rates. In addition, DACCS costs, input and output flows and carbon budgets have been aligned between models. Cost reductions have been applied to model technical learning, with an exogenous learning rate in TIAMGrantham and an endogenous one in WITCH. In both models, expansion constraints have been implemented as a $20 \%$ annual growth rate cap, according to historical benchmarks for technology development ${ }^{28}$ ). We impose the global maximum capacity at $30 \mathrm{GtCO}_{2} /$ year, in line with past NETs potential assessments $^{8-10,29,30}$. BECCS and afforestation are included in both models (see Supplementary Note 4 and Supplementary Table 1). 


\section{Table 1 Scenario overview}

$\mathrm{Gt}-\mathrm{gr} 20 \%$ Maximum capacity for DACCS plants limited to $3 \mathrm{Gt}_{\mathrm{CO}_{2}} /$ year, $20 \%$ annual growth

Gt - gr15\% Maximum capacity for DACCS plants limited to $3 \mathrm{Gt}_{\mathrm{CO}_{2}} /$ year, $15 \%$ annual growth

$\mathrm{Gt}-$ gr30\% Maximum capacity for DACCS plants limited to $3 \mathrm{Gt}_{\mathrm{CO}_{2}} /$ year, $30 \%$ annual growth

LowDisc

Low discount rate applied, close to $0 \%$ (see Supplementary Note 2)

LowStorage Limited storage availability, according to model characteristics (see Supplementary Note 3)

This table shows the scenario names and key characteristics. Note that all sensitivities apply to the DAC scenario, i.e. the scenario where all three of afforestation, BECCS and DACCS are available

\begin{tabular}{|c|c|c|c|c|}
\hline Technology & & $\begin{array}{l}\text { Electricity [GJ/ } \\
\left.\mathrm{t}_{\left.\mathrm{CO}_{2}\right]}\right]\end{array}$ & $\begin{array}{l}\text { Heat [GJ/ } \\
\left.\mathrm{t}_{\mathrm{CO}_{2}}\right]\end{array}$ & $\begin{array}{l}\text { Cost } \\
{\left[\$ / t_{\mathrm{CO}_{2}}\right]}\end{array}$ \\
\hline DAC1 & $\begin{array}{l}\text { High } \\
\text { Low } \\
\text { Floor }\end{array}$ & $\begin{array}{l}1.8^{6} \\
1.3^{17}\end{array}$ & $\begin{array}{l}8.1^{6} \\
5.3^{17}\end{array}$ & $\begin{array}{l}300^{19} \\
180^{17} \\
100^{17}\end{array}$ \\
\hline DAC2 & $\begin{array}{l}\text { High } \\
\text { Low } \\
\text { Floor }\end{array}$ & $\begin{array}{l}1.1^{22} \\
0.6^{68}\end{array}$ & $\begin{array}{l}7.2^{22} \\
4.4^{68}\end{array}$ & $\begin{array}{l}350^{6} \\
200^{38} \\
50^{70}\end{array}$ \\
\hline
\end{tabular}

This table shows the energy and cost assumptions for DACCS. Costs refer only to capital, labour and maintenance expenditure, while energy costs are determined endogenously by the models.

\section{Table 3 Carbon budgets imposed, $66 \%$ probability}

\begin{tabular}{ll} 
Climate target & Carbon budget 2016-210066 \\
\hline $2^{\circ} \mathrm{C}$ & $810 \mathrm{Gt}_{\mathrm{CO}_{2}}$ \\
$0.5^{\circ} \mathrm{C}$ & $220 \mathrm{Gt}_{\mathrm{CO}_{2}}$
\end{tabular}

This table shows the carbon budgets, defined as the cumulative $\mathrm{CO}_{2}$ emissions from 2016 to 2100 , for the climate targets. These are associated with a $66 \%$ probability to keep the temperature below 2 and $1.5^{\circ} \mathrm{C}$, respectively.

We focus on scenarios consistent with 2 and $1.5^{\circ} \mathrm{C}$ temperature increase limits. For each temperature scenario, we run three variant cases: one with only afforestation (NoNET scenario); one with afforestation and BECCS as per most published IAM-based studies (NoDAC); and a third one including DACCS in the mitigation portfolio (DAC). We perform sensitivity analysis on energy inputs, costs, growth constraints, discount rates and storage availability to test the robustness of model results. Table 1a summarizes all the scenarios.

Central case scenarios. DACCS has a significant influence on the mitigation pathway shape and the timing of peak emissions. Enabling DACCS as a technology option results in larger net emissions until around 2070, compensated by larger negative emissions thereafter in both models. In 2030 for a $1.5^{\circ} \mathrm{C}$ scenario, DACCS allows emissions to increase by between 10 and 25-30 $\mathrm{GtCO}_{2}$. These emissions are similar to those of $2{ }^{\circ} \mathrm{C}$ scenarios without DACCS. Conversely, at the end of the century in $1.5^{\circ} \mathrm{C}$ scenarios net negative emissions increase from 10 to $30 \mathrm{GtCO}_{2} /$ year.
Although similar levels of $\mathrm{CO}_{2}$ removal are present in some existing IAM scenarios ${ }^{3}$, these are as large as current net emissions (Fig. 1).

In terms of policy cost, DACCS reduces the marginal abatement costs to achieve the climate target by between 60 to more than $90 \%$. The 2030 global carbon prices with DACCS are below 100 and $200 \$ / \mathrm{tCO}_{2}$ for 2 and $1.5^{\circ} \mathrm{C}$ respectively (Fig. 1b). It should be noted that reaching a $1.5^{\circ} \mathrm{C}$ target without relying on NETs is infeasible for both models, highlighting the key role NETs can play in increasing the feasibility of ambitious climate targets. While questions arise about the inter-generational equity of these pathways, as DACCS allows a reduction in near term mitigation effort in some energy-intensive sectors that are difficult to decarbonize, such as transport and industry. Higher emissions are allowed from these sectors when a full portfolio of NET options is available (see Supplementary Fig. 1), and oil still accounts for a large share of the primary energy Supplementary up to 2050 (see Supplementary Fig. 2 and Supplementary Note 5).

DACCS appears to be a long-term mitigation measure, as it is largely deployed in the latter part of the century. Other NETs such as BECCS and afforestation are more evenly deployed over time, because they are more cost competitive (Fig. 2). Moreover, BECCS is able to produce carbon negative energy when it is deployed with new bioenergy capacity (as opposed to adding CCS to existing bioenergy capacity, which rather constitutes an energy penalty). By contrast, DACCS is treated by the models as a backstop to the exponential increase in the marginal abatement cost. It therefore substitutes for emission reductions more than other NET strategies, but does not provide a primary or secondary energy source for end-use services and requires additional primary energy supply.

In terms of the relation between different NETs, the total amount of CDR increases in line with the number of options that are available. There is some substitution: BECCS is reduced by $20-37 \%$ in DAC scenarios. Overall, though, both strategies are developed in tandem so as to avoid excessive specialization and consequently reduce risks and costs. Among the different DACCS options considered in TIAM-Grantham, the one based on solid amine sorbents (DAC2) appears the preferred one, especially with stringent mitigation. This can be related to residual emissions associated with burning natural gas for DAC1 heat provision (Supplementary Fig. 3a).

Figure 3 shows the implications for the electricity sector. DACCS long-term deployment reduces the need for a drastic decarbonization of the power sector. This is evident mainly from TIAM-Grantham results: in 2030 the electricity mix in DAC scenarios is not considerably different from Business-As-Usual, 


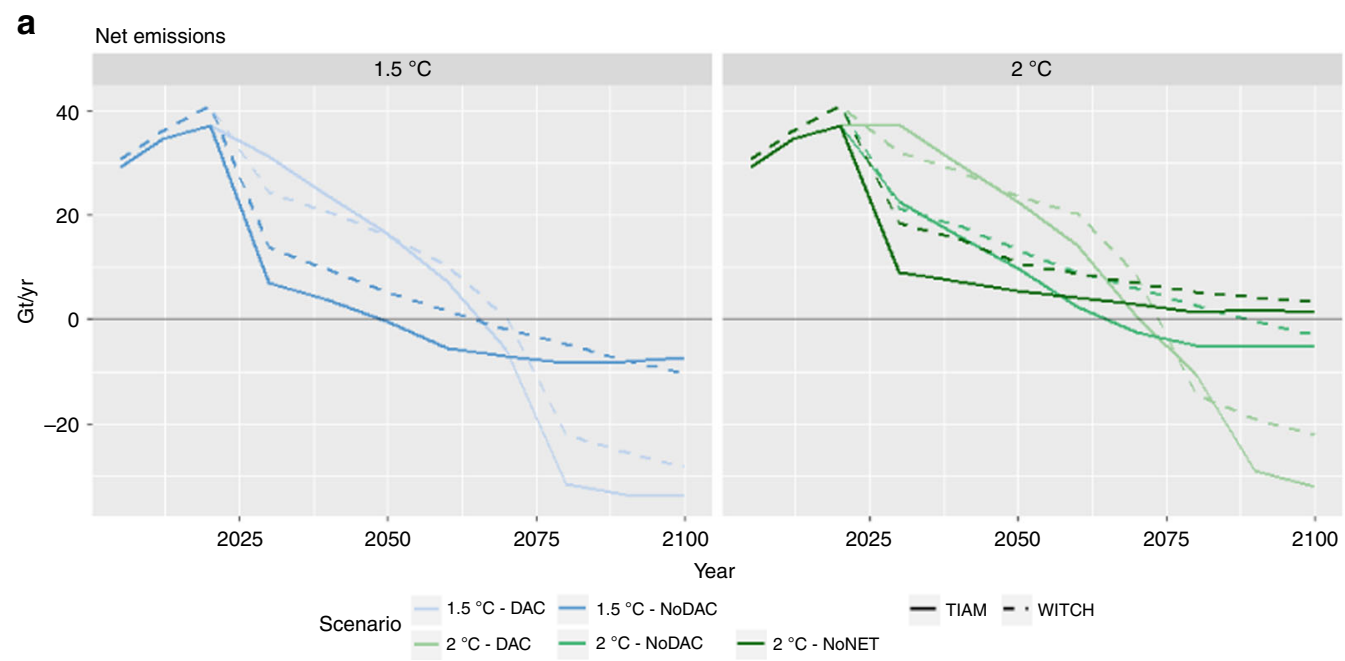

b

\begin{tabular}{|c|c|c|c|c|}
\hline Scenario & \multicolumn{2}{|c|}{$2{ }^{\circ} \mathrm{C}$} & \multicolumn{2}{c|}{$1.5^{\circ} \mathrm{C}$} \\
& TIAM & WITCH & TIAM & WITCH \\
\hline \hline DAC & 23 & 80 & 50 & 151 \\
\hline No DAC & 117 & 194 & 2119 & 446 \\
\hline No NET & 3711 & 272 & \multicolumn{2}{|c|}{ Infeasible } \\
\hline
\end{tabular}

Fig. $1 \mathrm{CO}_{2}$ emission pathways and carbon price in 2030 in central case scenarios. $\mathrm{CO}_{2}$ emissions (a) are from fossil fuel burning only, while the carbon price (b) is expressed in USD per ton of $\mathrm{CO}_{2}$
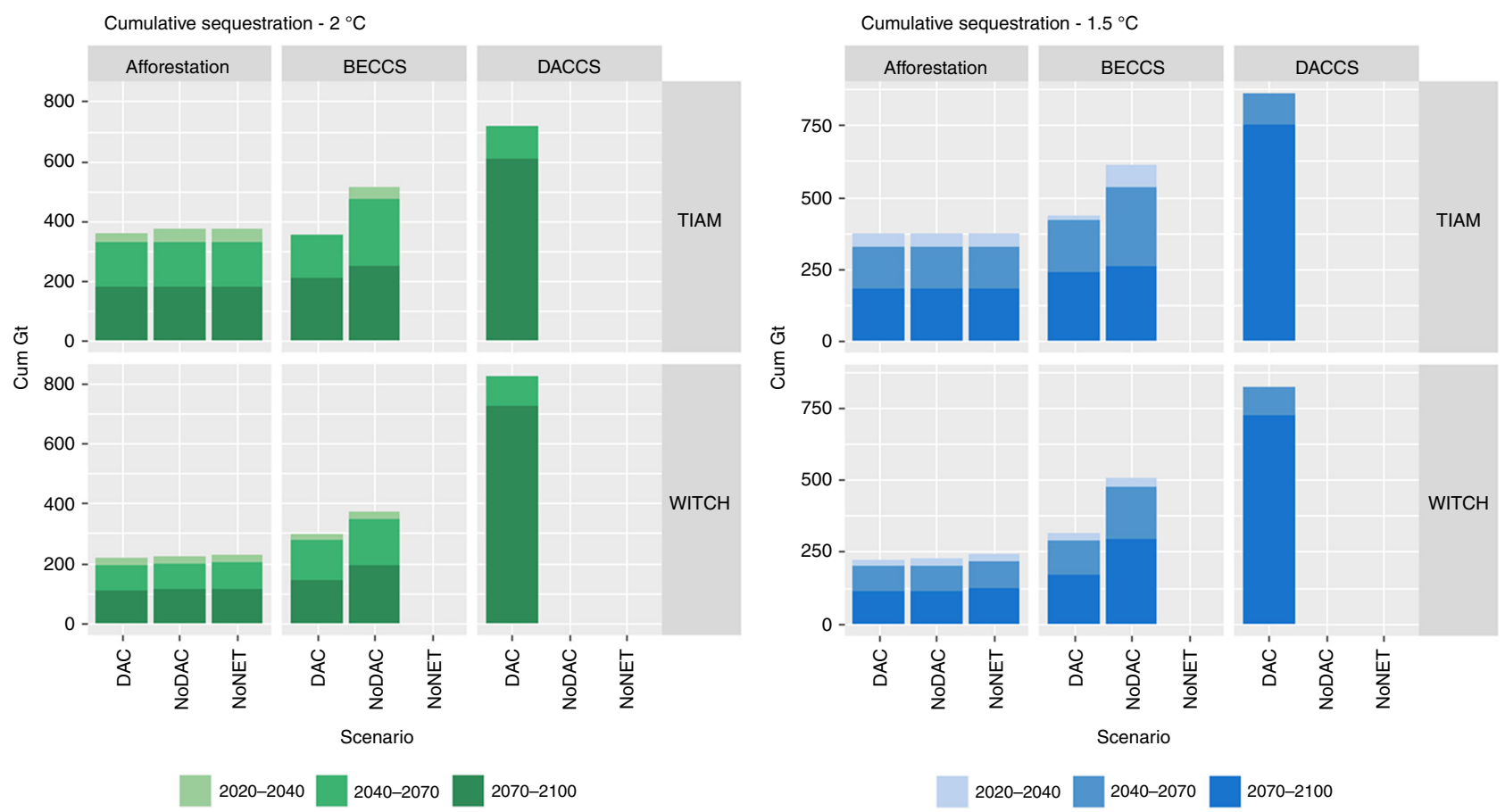

Fig. 2 Cumulative sequestration of negative emissions technologies throughout the century in central case scenarios, with different temperature targets. The short (2020-2040), mid (2040-2070), and long-term role (2070-2100) of each strategy has been highlighted

i.e. with no carbon constraint. Reaching a $1.5^{\circ} \mathrm{C}$ target relying only on BECCS and afforestation (NoDAC) requires $50 \%$ of electricity generation to come from intermittent renewable sources by 2030, and a higher electrification across sectors, increasing the overall electricity demand (up to $70 \%$ more than in DAC scenarios). Moreover, DACCS enables delaying the phaseout of fossil-based electricity generation until after 2050 .
Sensitivity on techno-economic parameters. Energy requirements and investment costs for DACCS are currently uncertain. However, sensitivity analysis with the two IAMs shows that the influence of these parameters is limited in determining the overall DACCS deployment (Fig. 4a). Only in TIAM-Grantham, with a $2{ }^{\circ} \mathrm{C}$ warming, lower energy consumption leads to $125 \mathrm{GtCO}_{2}$ more captured along the century. With a more stringent target 


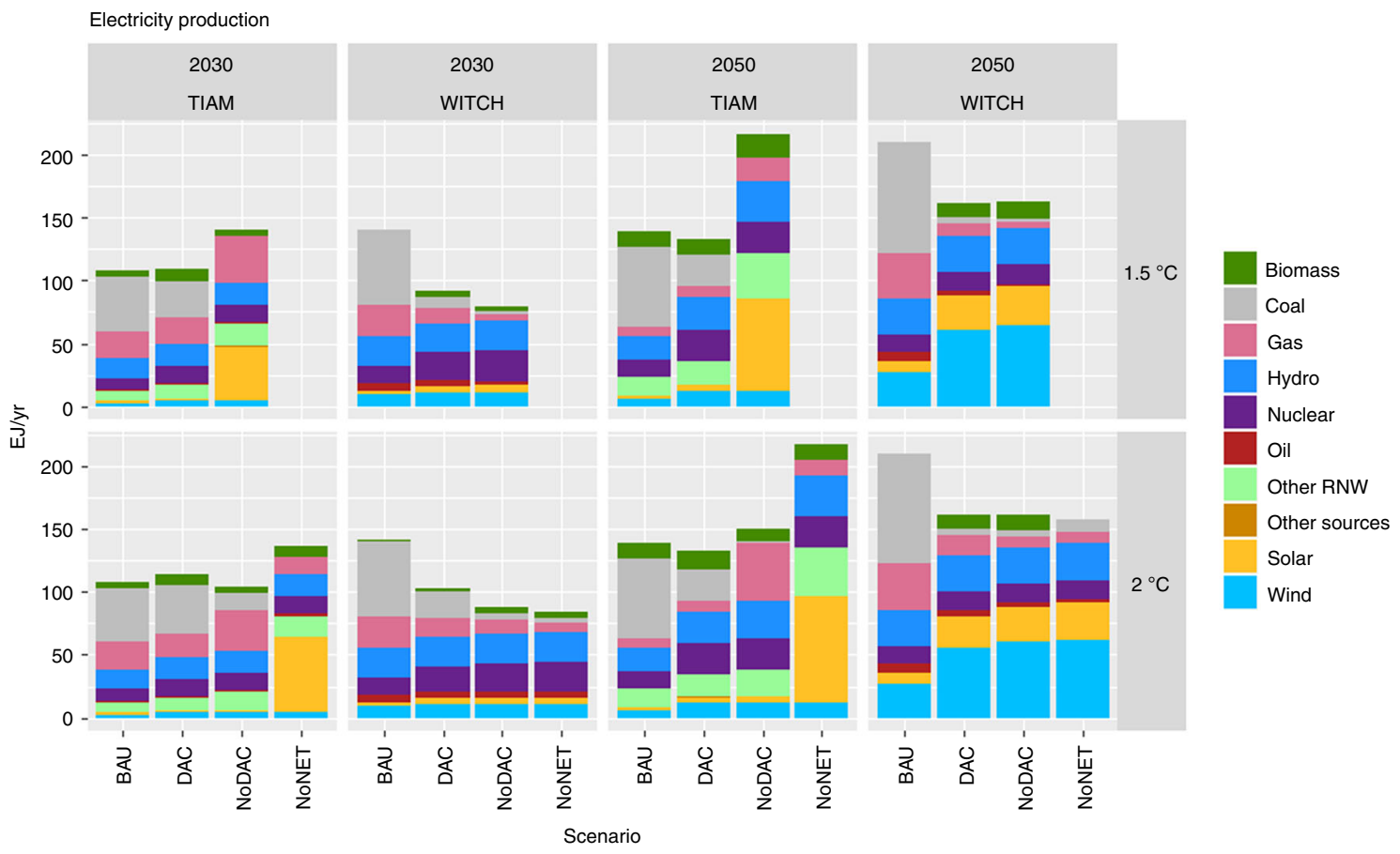

Fig. 3 Electricity mix in 2030 and 2050 in central case scenarios, compared to the Business-As-Usual (BAU). BAU assumes no mitigation policy to be implemented from 2020 on: economic and population growth are calibrated according to Shared Socio-Economic Pathways 2 in both models
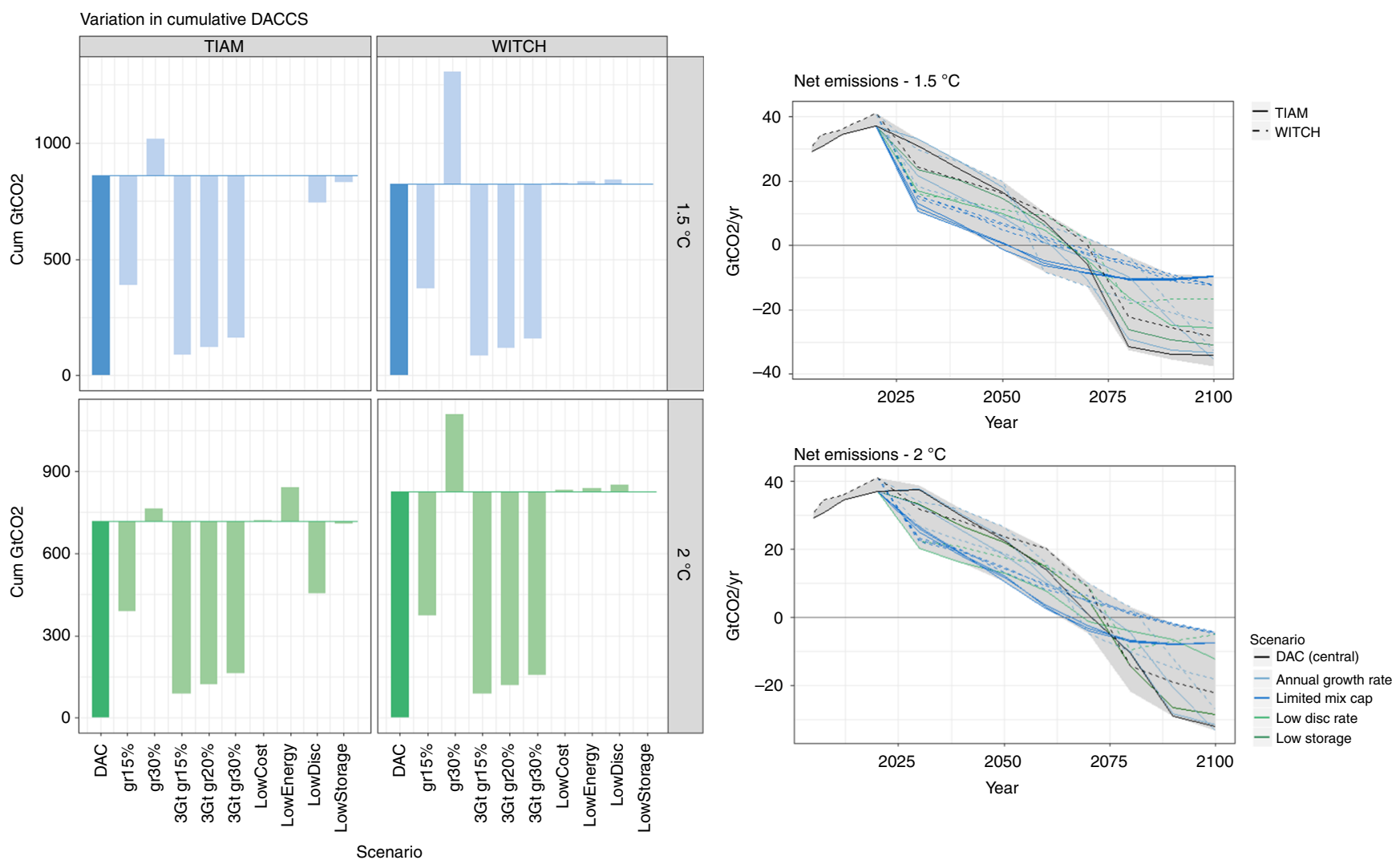

Fig. 4 Sensitivity on key parameters: in a light green bars show the change in cumulative sequestration by DACCS with respect to the base case (i.e. DAC scenario, represented by the first bar) across all sensitivities; b shows the emission pathway. Sensitivities have been grouped into four categories to highlight the most influential factors: those related to annual growth rates, maximum capacity, discount rates and storage availability. Energy and cost sensitivities are not included due to the limited impact of these parameters 


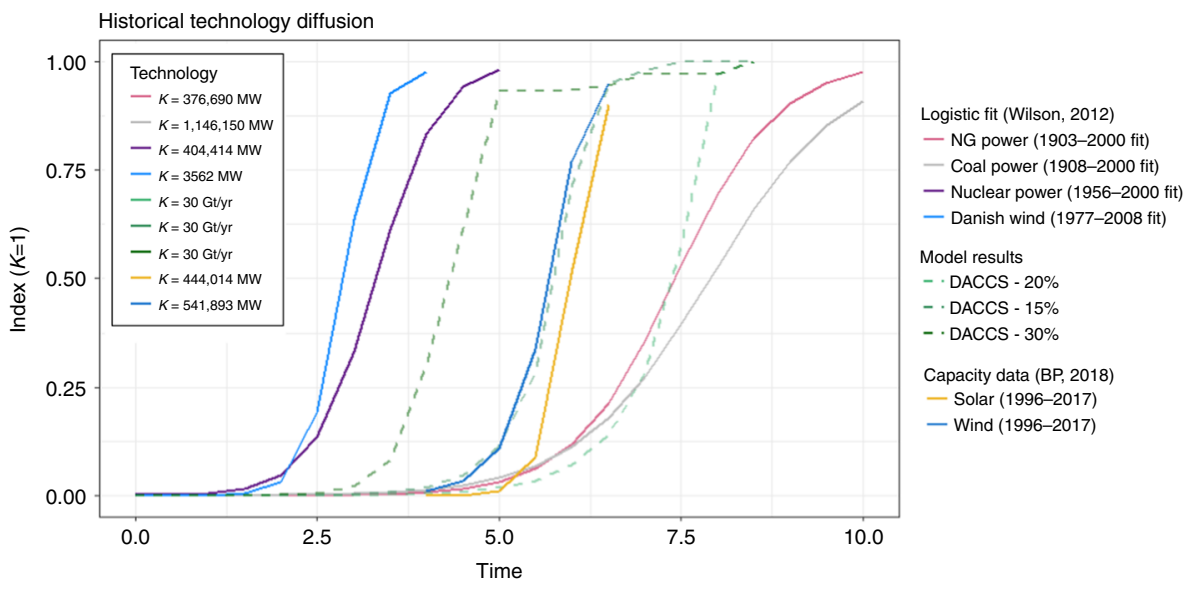

Fig. 5 Comparison of DACCS up-scaling with historical technology diffusion. Past technology diffusion pathways are based on data from Wilson ${ }^{33}$ and recent statistics for solar PV and wind ${ }^{35}$. As these technologies have been diffusing in different years and with different scales (i.e. the extent $K$ reached by the logistic profile), we have normalized the data indexing the capacity extent $K$ to 1 , and we have harmonized the starting year ( $t=0$ ), considering a unit time scale equal to one decade

$\left(1.5^{\circ} \mathrm{C}\right)$ this technology is deployed at the highest rate allowed, so that the only effect is on the share of the different DACCS technologies (see Supplementary Fig. 3b).

Conversely, expansion constraints are the key parameters determining DACCS deployment, especially for a $1.5^{\circ} \mathrm{C}$ target (Fig. 4a). This is in line with the existing literature ${ }^{8,9}$ but creates a high degree of arbitrariness as there are no obvious land or natural resource constraints, though unclear whether the very rapid scale-up indicated here is feasible in reality (this aspect will be investigated in more in detail in the next section). Changing the annual growth rate limit to 15 and $30 \%$ results in $\pm 450 \mathrm{GtCO}_{2}$ cumulative capture across the century. The impact on net emissions is more marked when limiting DACCS capacity to 3 $\mathrm{GtCO}_{2}$ /year. There is a strong reduction of residual emissions in the mid-term (Fig. 4b) and also repercussions on the energy sector (Supplementary Fig. 4a). DACCS cumulative sequestration is reduced by between 550 and $770 \mathrm{GtCO}_{2}$, while BECCS captures $\sim 20-50 \%$ more $\mathrm{CO}_{2}$ (Supplementary Fig. $4 \mathrm{~b}$ ).

Regarding inter-generational preferences, a lower time discount rate leads to earlier decarbonization in both models. This limits the need for large-scale carbon dioxide removal in later decades (Supplementary Fig. 5a). In TIAM-Grantham DACCS deployment is deeply affected, with cumulative sequestration decreasing by between 115 and $260 \mathrm{GtCO}_{2}$, in the 1.5 and $2{ }^{\circ} \mathrm{C}$ targets respectively. However, in WITCH it remains almost unchanged, while BECCS capacity is reduced (see Supplementary Fig. 5b). In both models, the impact is less marked for a $1.5^{\circ} \mathrm{C}$ target. In this case, all the options to remove $\mathrm{CO}_{2}$ are deployed at their maximum potential as there is less flexibility with regard to abatement timing.

With reduced $\mathrm{CO}_{2}$ storage availability, priority is given to DACCS with respect to other sequestration options, as its role cannot be substituted to tackle decentralized emissions. This results in less BECCS and CCS in both electricity and industrial sectors (Supplementary Fig. 6). As a consequence, electricity production relies more on renewables, and the resulting carbon price is approximately doubled (Supplementary Fig. 7).

Further information about sensitivity analysis can be found in Supplementary Note 6.

Historical comparison for scale-up rates. Results discussed so far show that the main issue is not related to costs but to the rate at which DACCS can be ramped up. Indeed, model runs show DACCS maximum scale-up rate being an average $1.5 \mathrm{GtCO}_{2}$ /year, about twice the maximum rate of BECCS in similar mitigation scenarios ${ }^{15}$. Historical data can been used for benchmarking growth rates, so to help understand the feasibility of the foreseen diffusion pathways for DACCS. Typical historical rates are between 15 and $20 \%$ per year ${ }^{28}$, with the high end referring to modular technologies, rather than large scale complex facilities (see Supplementary Table 2). Indeed, DACCS technology allows smaller scale and relatively finer granularity compared to BECCS plants. The recent diffusion of solar PV at about $30 \%^{31}$ and forecasts for wind, expected to grow at $11 \%$ per year until $2050^{32}$ are aligned with the rapid scale-up of DACCS seen in our results.

Historical diffusion pathways have been modeled through logistic curves 33,34 . These allow the analysis of the entire life-cycle of technologies in terms of up-scaling, formative phase and saturation, thereby not focusing only on a limited time span of rapid growth. We compare DACCS growth profiles from our models with historical cases, including the logistic fit obtained by Wilson $^{33,34}$ for different energy technologies and the recent diffusion of solar PV and wind capacity ${ }^{35}$ (Fig. 5). Even if DACCS deployment may appear incredibly rapid, from 1 to $30 \mathrm{GtCO}_{2} /$ year of removal in only 20 years, other technologies experienced similar patterns in the past.

This ambitious up-scaling pathway requires appropriate regulatory interventions and public acceptance: in practice, these could prove complex and challenging, in light of the experience of CCS has demonstrated limited societal support ${ }^{36}$. Currently, literature studies on NETs have focused extensively on the supply side of technology development, not addressing other key issues related to incentives for early deployment, niche markets and the regulatory framework ${ }^{15}$. Indeed, policy instruments and financial incentives supporting negative emission technologies are almost absent at a global scale, though essential to make NET deployment attractive, generating revenues linked to the carbon dioxide captured by these plants for instance ${ }^{37}$.

Energy land water and material use. An other key parameter in our models is the maximum DACCS capacity in terms of $\mathrm{GtCO}_{2}$ captured. This is directly related to the number of plants that can be built, the energy input to operate them and the environmental impact in terms of land, water and material use. We investigate the implications of our scenarios on these aspects (results are shown in Supplementary Table 3).

If large-scale plants are going to be built ${ }^{6}$ (i.e. $D A C 1$ technology), capturing $30 \mathrm{GtCO}_{2} /$ year means installing 30,000 
a
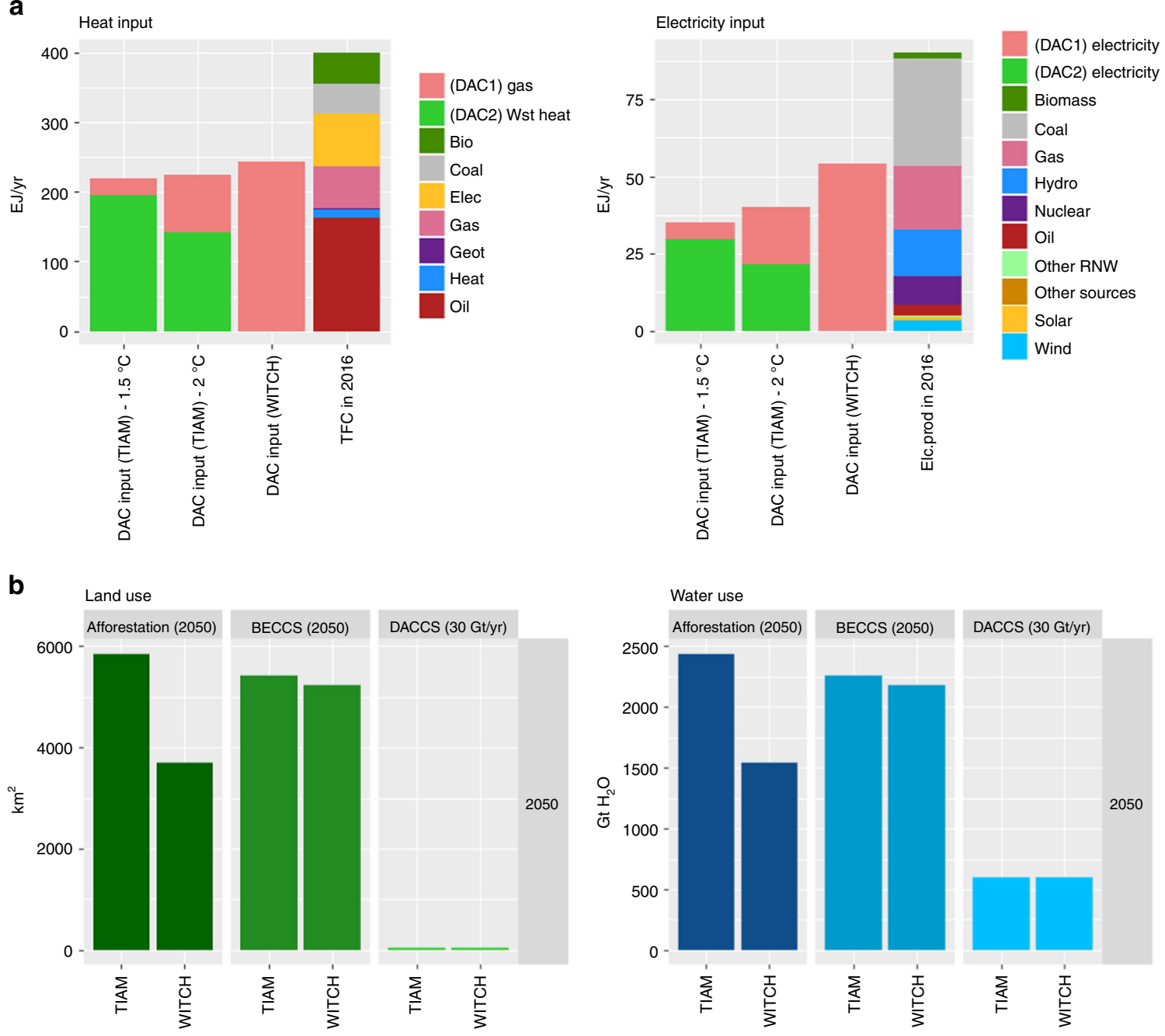

Fig. 6 Impact of DACCS in terms of energy input, land and water use. a shows the energy input required to operate DACCS plants capturing about 30 $\mathrm{GtCO}_{2}$ /year. Note that from TIAM-Grantham we have a differentiation among the two DACCS technologies, with different heat sources, while in WITCH we only have gas-fired DAC1 plants. Heat and electricity inputs are compared with the 2016 Total Final Consumption and electricity production respectively, as reported by the International Energy Agency 43 . b shows the amount of land and water used by DACCS plants to capture $30 \mathrm{GtCO}_{2} / \mathrm{year}$ compared to BECCS and afforestation ${ }^{5}$, when these are deployed at the levels foreseen by the models in 2050

facilities. This is comparable with the cumulatively produced number of jet aircraft $\left(21,000\right.$ in $\left.1958-2007^{33}\right)$ or natural gas plants $\left(15,000\right.$ in $\left.1903-2000^{33}\right)$ built in the past. By contrast, considering Climeworks's design ${ }^{38}$ (i.e. DAC2), around 30 million units could be required in operational stock by the end of the century. This is aligned to the world annual market for cars and commercial vehicles (73 million unit in $2017^{39}$ ).

Past studies have investigated environmental implications of different CDR options ${ }^{4,5,40-42}$. Conversely to BECCS, there are fewer external constraints that may limit the deployment of DACCS a priori, as land and water use is significantly reduced compared to biological NETs (see Fig. 6b). Nevertheless, DACCS will have a significant impact on global energy provision.In 2100 it could require around $50 \mathrm{EJ} /$ year of electricity, that is more than half of today's total production ${ }^{43}$ (and about $10-15 \%$ of the global generation projected in 2100 by our models) and $250 \mathrm{EJ} /$ year of heat, representing more than half of today's final energy consumption globally ${ }^{43}$ (Fig. 6a). It should be noted that providing around $200 \mathrm{EJ} /$ year of waste heat may have implications on the locations of DACCS plants: in order to avoid additional infrastructure and pipelines, these need to be colocated close to industrial facilities where waste heat is recovered, partially limiting the decentralization advantage of this technology. Nevertheless, this represents only one technological option to realize direct air capture: different sources of heat can be used according to site-specific availability, enabling a sufficient level of flexibility.

Moving to material use, we investigate the availability and the production process of the proposed chemical sorbents at large scale. Hydroxide solutions are currently obtained as a sideproduct of chlorine $\left(\mathrm{Cl}_{2}\right)$ synthesis, which is the main market product. High DACCS deployment would reverse these roles, with sodium or potassium hydroxide becoming the most valuable output, thus disrupting the current market. Considering the sorbent replacement rate in DAC1 plants ${ }^{18}$, the current scale of the chlorine market of about $80 \mathrm{Mt} /$ year $^{44}$ will allow capture of 300-500 $\mathrm{MtCO}_{2}$ /year. Moreover, sodium hydroxide is produced through an energy intensive chloralkali process, so that an additional 2.2-3.8 GJ of electricity is required per ton of $\mathrm{CO}_{2}$ captured. This is more than twice the electricity required to operate DACCS plants. For amine adsorbents, it is more difficult to investigate their impact as few technical details are available in the literature. As with amine sorbents employed for traditional CCS (MEA, monoethanolamine), synthesis is likely to start from 
a

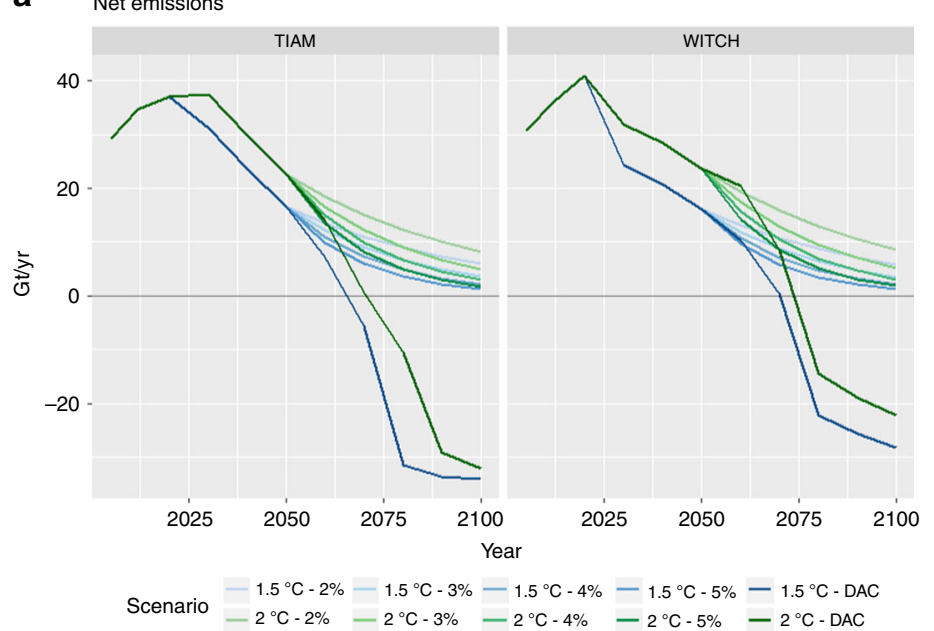

b

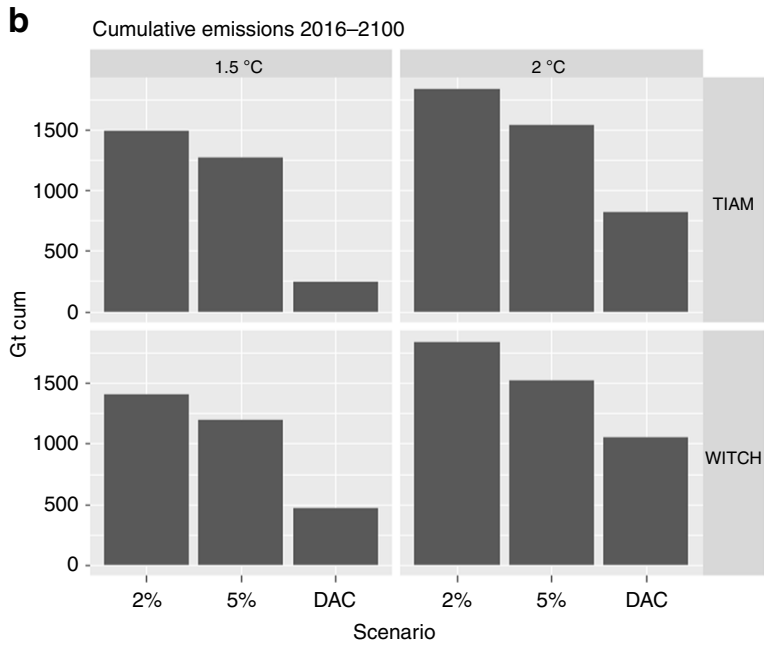

Fig. 7 Emission pathway and cumulative emissions in DACCS failure scenarios. The left panels a shows the emission pathways of the original DACCS scenarios and those with no DACCS and exogenous emission reductions between 2 and 5\%. The right panels b show the 2016-2100 cumulative emissions of $\mathrm{CO}_{2}$. In this case, carbon emissions for WITCH include both fossil burning, industry and land use

ammonia and ethylene oxide. Their markets are about $177^{45}$ and $35^{46} \mathrm{Mt} /$ year, respectively, and they both come from fossil fuel feedstock. Based on MEA production process ${ }^{47}$ with a similar replacement rate to DAC1 plants, $15-26 \mathrm{Gt} /$ year of ammonia and 3-5 Gt/year of ethylene oxide will be required. These are approximate calculations, as the long-term sorbent stability is still unknown ${ }^{48}$, but they provide a starting point to understand the challenges behind such a scale-up of DACCS. These comparisons highlight the requirement for more detailed process-scale operational data and techno-economic assessments for policy makers to understand the full costs and potential of DACCS.

Carbon cycle feedback. An important issue to be considered is the behaviour of natural carbon sinks to negative emissions, that may hinder the effectiveness of NETs ${ }^{49-52}$. Past studies using Earth System Models ${ }^{51}$ estimate that removing $491 \mathrm{GtCO}_{2}$ from the atmosphere over a period of 30 years $\left(16 \mathrm{GtCO}_{2} /\right.$ year $\mathrm{GtCO}_{2} /$ year) or 10 years ( $49 \mathrm{GtCO}_{2} /$ year) would result in 51 or $95 \mathrm{GtCO}_{2}$ outgas emissions from the oceans respectively. From our scenarios, DACCS is foreseen to remove between 16 and $30 \mathrm{GtCO}_{2}$ /year over the period 2070-2100. This implies that a significant fraction (from 10 to 19\%) of the carbon removed would be released back to the atmosphere from the oceans, requiring an additional removal of 1.7 to $9.5 \mathrm{GtCO}_{2} /$ year to meet the same carbon budget. Indeed, accounting for carbon cycle feedbacks within IAMs has been shown to decrease the attractiveness of $\mathrm{CDR}^{8}$.

What if DACCS fails to deploy at scale?. Given the stillsignificant uncertainties about NETs feasibility, we seek to understand the impact of relying on NETs to reach mitigation targets, only to find out later that they do not perform as anticipated. The emission pathways shown in Fig. 7a follow DAC scenarios up to 2050. After that date we assume that no DACCS (and no BECCS/afforestation) is going to be installed, and we simply apply a set of exogenous emission reduction rates varying between 2 and 5\% per year. These are aligned with historic emission reduction rates achieved in some countries for consecutive years ${ }^{53}$, and are meant to simulate the ambitious efforts in the absence of carbon removal strategies. Nevertheless, these decarbonization rates could conceivably be exceeded, so they are used purely as an illustrative range, subject to high uncertainty. Not having NETs after mid century increases cumulative emissions between 600 and $1200 \mathrm{GtCO}_{2}$. Considering a transient climate response to cumulative emissions (TCRE) to be in the range of $0.8-2.4^{\circ} \mathrm{C} / \mathrm{TtC}^{54}$, not having DACCS leads to a temperature overshoot by the end of the century of $0.15-0.8^{\circ} \mathrm{C}$, according to the range of emission reduction rates investigated. That is, targeting $1.5^{\circ} \mathrm{C}$ with DACCS and then not having it would likely lead to a warming of $2^{\circ} \mathrm{C}$ and more.

It should be noted that this temperature change estimate does not account for any additional reduction in mitigation effort that the assumption of future emissions removals could have, based on moral hazard considerations. These deterrence effects, that result in NETs substituting for emission reductions rather than supplementing them, include also rebounds and side-effects (e.g. land-use change, use of captured $\mathrm{CO}_{2}$ in enhanced oil recovery) and may result in a larger temperature increase by the end of the century $^{55}$. It is therefore essential that policy makers make informed decisions so as to undertake early mitigation with a full consideration of these risks ${ }^{56}$, as well as an appropriate reflection of the economic costs, which future generations can reasonably bear.

\section{Discussion}

Our analysis shows that in theory DACCS can be an enabling factor for the Paris Agreement objectives: it allows their achievement at lower costs, by more-than-halving carbon prices in 2030. This follows from the reduction of near-term mitigation in exchange for higher long-term atmospheric $\mathrm{CO}_{2}$ removal by DACCS technologies, which includes a delayed phase out of fossil fuels from the power sector until after 2050.

The analysis also highlights the clear risks of planning a longterm mitigation strategy on the assumption that DACCS will be available and can scale up at speed. First, we find that the speed of DACCS scale-up is the greatest sensitivity in its ability to remove $\mathrm{CO}_{2}$ and ease the mitigation burden on the energy system. A failure to achieve this scale-up risks locking the energy system into fossil fuels and making the long-term temperature goal much more costly and less feasible. Second, whilst the analysis posits that the indicated DACCS scale-up may not be unprecedented when compared to some other technologies (notably jet aircraft), it highlights several potential barriers to deployment. These 
include the chemical pollutant implications of sorbent manufacture at vast scales, as well as a requirement to use around a quarter of global energy demand to provide power and heat for DACCS technologies by the end of the century. Therefore, it is important to include DACCS within a diversified mitigation portfolio in low carbon scenarios, together with other CDR strategies, demand-side and lifestyle measures ${ }^{36,57}$. We recommend that further analysis undertake a full life-cycle assessment of DACCS, in order to understand how its deployment drives energy demand for sorbent manufacture, as well as energy and material demand such as cement and steel for DACCS equipment. Finally, the scale-up of DACCS indicated would only be possible with an appropriately comprehensive $\mathrm{CO}_{2}$ transport and sequestration infrastructure, as well as a strong regulatory and planning framework and public acceptability. Given the challenge of addressing these barriers, it is instructive to highlight that failure for DACCS to materialise, when previously planned for, could lead to up to $0.8^{\circ} \mathrm{C}$ of warming overshoot.

Given the limits of IAMs in accounting for such risks, our preliminary considerations should be supplemented with further analysis and an appropriate theoretical framework ${ }^{58-60}$ accounting for interactions between technologies, society and political power, so to highlight optimal mitigation strategies in light of the uncertainty of future DACCS deployment and governance.

The potential economic benefit from DACCS, whilst considerable, must be weighed up against a fuller analysis of its technical viability and scale-up potential, in light of all of the challenges highlighted above. Given the urgency and importance of achieving the Paris Agreement goals, we recommend to policy makers that they support an acceleration in development and deployment of DACCS, but without easing near-term mitigation efforts ${ }^{60}$, so as to manage the risk of DACCS underperformance or failure.

\section{Methods}

Study design. This study is based on modeling long-term mitigation scenarios using two IAMs: TIAM-Grantham ${ }^{61,62}$ and WITCH ${ }^{63,64}$. We model climate targets by imposing a carbon budget over the period 2016-2100 equal to 810 and 220 $\mathrm{GtCO}_{2}$, consistent with $2^{\circ} \mathrm{C}$ and $1.5^{\circ}$ warming respectively ${ }^{65,66}$. In addition to the sequestration options already implemented in the models (CCS in electricity and industrial sectors, afforestation and BECCS), we include also a technology to capture $\mathrm{CO}_{2}$ directly from the air and store it under the ground, namely DACCS. We differentiate costs and energy inputs according to the literature, including cost reduction over time due to technical learning, and we implement growth constraints to model a feasible deployment rate within the models.

In addition, an expert elicitation was conducted to better understand the potential of this new technology from the perspective of specialists currently researching in this field, given the fragmentary and limited literature available on this topic.

The inter-model study design ensures that our results are robust across model uncertainties, as the IAMs adopted have complementary characteristics, combining a detailed bottom-up energy system model (TIAM-Grantham) and a hybrid model $(\mathrm{WITCH})$ with a top-down representation of macro-economic variables. To test robustness against parametric uncertainty, we perform a sensitivity analysis on cost and energy parameters, annual growth rates and maximum capacity levels, as well as investigating the impacts of limited $\mathrm{CO}_{2}$ storage capacity and a lower time discount rate. A detailed description of the IAMs adopted can be found in Supplementary Note 1, together with further information about time discount rates (Supplementary Note 2), storage availability (Supplementary Note 3) and CCS/ BECCS cost assumptions (Supplementary Note 4).

In addition, it should be noted that WITCH includes carbon emissions from fossil fuel and industry (FFI) and from the land use sector, while TIAM-Grantham only considers FFI emissions. In both 1.5 and $2{ }^{\circ} \mathrm{C}$ scenarios, net cumulative landuse emissions over the century in WITCH are close to zero.

Modeling DACCS technologies. Looking at the state of the art for capturing $\mathrm{CO}_{2}$ directly from the air, research has focused on the application of aqueous hydroxide solutions (DAC1) and amine-modified solid sorbents (DAC2). These two technologies are employed in the first DACCS plants built around the world, and therefore closer to being commercially available; other innovative solid sorbents have not been included as they are still at an earlier research stage. We characterize these two processes in terms of cost and energy inputs: while in TIAM-Grantham we implement both $\mathrm{DAC} 1$ and $\mathrm{DAC} 2$, given the technological details allowed by this model, in WITCH we only include the former.

DAC1 technology refers to the first plant design proposed by the American Physical Society (APS) in $2011^{6}$ and further developed through the work of Keith and Holmes ${ }^{17,20}$, together with the company Climate Engineering. It is based on a two-loop hydroxide-carbonate system $(\mathrm{NaOH}-\mathrm{CaOH}$ or $\mathrm{KOH}-\mathrm{CaOH})$, with a plant reference size of $1 \mathrm{Mt}$ /year of captured $\mathrm{CO}_{2}$. This design involves large energy needs, mainly high-temperature heat for sorbent regeneration that can be provided by burning natural gas: electricity requirements range between $1.3^{17}$ and $1.8^{6} \mathrm{GJ} /$ $\mathrm{tCO}_{2}$, and heat input between $5.3^{17}$ and $8.1^{6} \mathrm{GJ} / \mathrm{tCO}_{2}$. An additional CCS unit is needed to capture the $\mathrm{CO}_{2}$ emitted when burning natural gas, with a capture efficiency equal to $95 \%$, similar to natural gas combined cycle (NGCC) plants with oxyfuel CCS already implemented in both models.

The second option, DAC2, is based on amine-functionalized adsorbents ${ }^{67}$, currently under development by Climeworks in Switzerland and Global Thermostat in the US. Few technical details are available, due to commercial confidentiality. Solid sorbents have lower energy consumption, given the lower regeneration temperature (electricity: $0.6^{68}-1.1^{22} \mathrm{GJ} / \mathrm{tCO}_{2}$, heat: $4.4^{68}-7.2^{22} \mathrm{GJ} /$ $\mathrm{tCO}_{2}$ ). Significant cost reductions are expected in the future, both because of its modular design and the low level of technological maturity. As the lowtemperature heat may be provided through heat recovery, the energy input has been modeled as a waste heat stream coming from industrial processes and lowcarbon power plants. This allows a reduction of the overall cost of capture, as energy needs appear to be one of the main cost components for DACCS plants. The main drawbacks for DAC2 are degradation and stability issues related to the amine materials, leading to higher operational expenditure due to sorbent replacement.

We use scientific papers to determine the higher cost bounds, and estimates from private companies running the first demonstration plants to define the low cost scenario and the floor value, as summarised in Supplementary Table 4. The operating expenditure reported does not include energy costs, as these are determined endogenously by the models.

For DAC1, Mazzotti's optimization on the APS design ${ }^{19}$ provides the high cost scenario, with an overall cost around $300 \$ / \mathrm{tCO}_{2}$ (excluding energy), while the latest paper by Keith and Holmes issued in June $2018^{17}$ gives both the low cost estimates $\left(180 \$ / \mathrm{tCO}_{2}\right)$ and the target for future cost reduction, around $105 \$ / \mathrm{tCO}_{2}$. Both these references provide a detailed cost breakdown, enabling specification of CAPEX and OPEX, as well as individual cost components. Combined with lowcost renewable energy, for example in North Africa, this cost can be even lower ${ }^{69}$ The high floor cost reflects DAC1 limited potential for future cost reductions, as this technology is based on processes and equipment already well-known and developed in other sectors.

Capture plants based on amine-modified adsorbents (DAC2) are characterized by higher operational costs due to frequent sorbent replacement because of degradation. As no exhaustive cost assessments for this technology are publicly available, we start from the APS 6 estimate for the overall capture cost $\left(350 \$ / \mathrm{tCO}_{2}\right.$ without energy), but switch the fraction allocated to OPEX and CAPEX (74 and $26 \%$, respectively), to reflect the specifics of this technology option. We use the same percentage allocation of overall costs between CAPEX and OPEX for the low and the floor cost estimates. The low cost scenario is defined according to Climeworks' estimate ${ }^{38}\left(200 \$ / \mathrm{tCO}_{2}\right)$, while the floor cost of $50 \$ / \mathrm{tCO}_{2}$ is that claimed by Global Thermostat ${ }^{70}$.

Floor cost identifies the long-term target that could be achieved in the future, and is used to set a lower bound for cost reduction. In both IAMs cost reduction is implemented to model technical learning over time, with an exogenous rate in TIAM-Grantham (6\% per year, aligned with historical cases in energy and chemical sectors ${ }^{71}$ ) and an endogenous learning curve in WITCH (learning rate equal to 0.06 , the same used for natural gas plants with CCS).

Information on techno-economic parameters are summarized in Supplementary Table 4 and Supplementary Fig. 8.

Waste heat recovery in TIAM-Grantham. As explained earlier, waste heat can be employed to operate amine-based plants and it is already implemented in Climeworks' and Global Thermostat's pilots. We include this aspect in TIAMGrantham, given its detailed technological representation of the energy system. We define a new commodity to model the waste heat recovered both from energyintensive industrial processes (e.g. pulp and paper, iron and steel production) and from the power sector. As the waste heat potential will be limited, two distinct processes to represent amine-based DACCS have been defined, namely DAC2 and DAC21 (see Supplementary Fig. 8): heat is supplied through waste heat to the former, and through heat made on purpose to the latter. They are characterized by same economic and technical parameters, so that the model is free to install as much capacity of amine-based plants deploying DAC21, with no constraints deriving from the availability of the waste heat commodity. From our results DAC21 is almost never installed, as it is not economic to produce heat solely to fuel DACCS plants

To determine the recovery potential of industrial waste heat, we use analysis by Ecofys $^{72}$, which examines a number of heat-intensive industrial sectors, such as refineries, iron and steel, ceramics, glass, chemicals, food, drink and pulp and paper 
industry. Referring to this data, we identify the sectors where the new commodity may be applicable and we define the production of waste heat as a fraction of the energy input, with this recovery factor $R F$ changing according to the industry, as shown in Supplementary Table 5. As in our recovery process the sink is represented by the amine regeneration step, taking place at temperatures below $120^{\circ} \mathrm{C}$. Only industrial heat flows with temperature equal to or higher than $140^{\circ} \mathrm{C}$ examined in the report have been taken into account. We put a cap on the capacity of industrial processes connected with waste heat, to avoid the model over-installing them only to provide the heat needed by DACCS plants. The constraint is based on the capacity installed in a baseline scenario without DACCS, with a $2{ }^{\circ} \mathrm{C}$ mitigation target.

Waste heat was also allowed to be sourced from some low-carbon power plants, namely nuclear and concentrated solar power. In the first case, waste heat can be recovered from the steam cycle in addition to the primary electricity output, while in the latter case, heat is produced as in Combined Heat and Power (CHP) units, slightly reducing the primary electricity outflow.

For nuclear plants, electricity generation efficiency is about $33 \%$, meaning that about two-thirds of the energy in the fuel is lost and dissipated to the environment as heat. The temperature of the dissipated heat is sufficiently high to be supplied to amine-based DACCS plants, therefore in TIAM-Grantham all existing nuclear processes have been specified to include waste heat as an auxiliary output commodity (in addition to electricity). The overall efficiency of cogenerative plants is usually about $80 \%$, including an electrical efficiency $\eta_{e l}=35 \%$ and a thermal efficiency around $45 \%{ }^{73}$. Therefore, for each PJ unit of electricity in output, $1.3 \mathrm{PJ}$ of waste heat may be obtained $\left(R F_{\text {nucl }}\right)$.

$$
R F_{\text {nucl }}=\frac{Q_{\text {wst }}}{W_{\text {el }}}=\frac{\eta_{\text {th }}}{\eta_{\text {el }}}=\frac{0.45}{0.35}=1.3
$$

Conversely, a new process has been defined to differentiate Concentrated Solar Power (CSP) plants where heat can be recovered (CHP mode) from those only producing electricity. This technology will use a steam power plant with backpressure configuration, that means the electricity output is reduced, increasing the temperature at the steam turbine outlet to be sufficiently high to allow heat recovery at the condenser. Therefore, CHP solar plants (CSP-CHP) will have lower electrical efficiencies, going from $\eta_{e l, C S P}=20 \%$ to $\eta_{e l, C S P-C H P}=15 \%{ }^{74}$. As costs are allocated to a reduced electricity output, this technology will be treated as more costly in the model with respect to traditional CSP plants. The recovery factor $R F_{C S P}$ is computed considering a recovery efficiency for the heat output at the condenser $\eta_{t}$ equal to $80 \%^{74}$.

$$
R F_{C S P}=\frac{Q_{w s t}}{W_{e l}}=\left(\frac{1}{\eta_{e l, C S P-C H P}}-1\right) \cdot \eta_{t}=4.53
$$

\section{Comparison with historical technology diffusion. We compare DACCS}

deployment pathways from our results with other historical technology diffusion in order to understand its feasibility. We start from the work done by Wilson ${ }^{33,34}$ to model scaling dynamics across a range of technologies. This describes the common s-shaped growth profile with logistic function parameters, starting from historical time series data on refineries, power plants (nuclear, coal, gas, wind), jet aircraft, cars and lightbulbs. As these studies demonstrate a consistent relationship between the extent and the rate of scaling, measured in terms of cumulative total capacity, we use the same dataset as a benchmark to validate our projections for DACCS uptake up to 2100 . Given that each technology is characterized by a different extent (i.e. maximum level of capacity reached during saturation phase) and their upscaling takes place during different time periods, we normalize the data, indexing the capacity extent $K$ to a value of 1 , and consider a general timescale, with $t=0$ representing the starting year of diffusion (first unit installed), and each unit of time corresponding to one decade $(t=1$ coincides with 10 years later than the starting one).

In addition to this historical data, mainly referring to the 20th century, we have included also time series data about the recent rapid growth of low-carbon technologies, such as solar PV and wind, using British Petroleum statistics up to $2018^{35}$.

Impact assessment for DACCS technologies. According to the assessment made by Smith ${ }^{5}$ on physical and economic impacts of large scale NETs deployment, one of the advantages of DACCS is the reduced footprint with respect to BECCS or afforestation, in terms of water and land use and sustainability implications (values adopted are summarized in Supplementary Table 6). Considering a sustainable bioenergy supply for BECCS plants, we have explicitly imposed a limit of $200 \mathrm{EJ} /$ year in TIAM-Grantham, according to a past assessment ${ }^{75}$, that results within the range of models used in RF1.9 scenarios ${ }^{66}$. In WITCH this limit is not explicit, but it is never hit. Differently, there are no external constraints that may limit the deployment of DACCS a priori, such as material scarcity or environmental footprint, while a major issue is likely to come from the provision of chemical sorbents. Moreover, DACCS offers an additional location flexibility so that the capture facility can be placed closer to geological sequestration sites, avoiding long pipelines.

According to Smith et al. ${ }^{5}$, the land footprint related to BECCS power plants is between 270 and $1636 \mathrm{~m}^{2}$ to capture 1 tonne of $\mathrm{CO}_{2}$ per year, depending on the type of feedstock used as input fuel: the lower end corresponds to purpose-grown crops, while more land is required for agricultural residues due to their lower energy yield. Similar values can be applied also to afforestation, as they are both biological sequestration strategies. For DACCS, it is difficult to quantify the amount of land needed, given that there are currently so few pilot plants and each of the proposed designs require different plant components. Generally, the amount of land needed is limited to the one for building plant facilities, due to the low risk of build-up of $\mathrm{CO}_{2}$ deficient air around the capture plant ${ }^{21}$. Amine-based plants would require around $0.05-0.1 \mathrm{~m}^{2} / \mathrm{tCO}_{2} /$ year ${ }^{12,13}$, while those using hydroxide solutions around $1.5 \mathrm{~m}^{2} / \mathrm{tCO}_{2} / \mathrm{year}^{6}$. The land footprint could increase considerably if solar PV panels or wind turbines were used to provide energy required, though unproductive land supplying minimal ecosystem services could in principle be allocated as sites.

Estimates for water requirements to remove one tonne of carbon by DACCS are about one order of magnitude or more lower than for BECCS plants, as BECCS demands water both for growing crops and feedstock and for operating the CCS module. Again, similar values can be applied to afforestation ${ }^{5}$. Water loss may represent a concern for some DACCS systems: aqueous systems are prone to evaporation, leading to a consumption of about 5 to 13 tonne of water per each tonne of carbon dioxide captured during normal operation, depending on humidity and air temperature ${ }^{14,76}$. Developers of amine-based plants do not mention water use as a source of concern, but other solid sorbents tested for DACCS application ${ }^{24}$ may require up to 20 tonnes of $\mathrm{H}_{2} \mathrm{O}$, so that this has been taken as the high end for our assessment.

Considering the material use, the production of hydroxide sorbents is not straightforward, as a large amount of energy is required to synthesize sodium hydroxide $(\mathrm{NaOH})$ and potassium hydroxide $(\mathrm{KOH})\left(13.3 \mathrm{GJ} / \mathrm{t}_{\mathrm{NaOH}}\right.$ and $7 \mathrm{GJ} /$ $\mathrm{t}_{\mathrm{KOH}}{ }^{77}$ respectively). Moreover, currently these chemicals are obtained as a side product from chlorine $\left(\mathrm{Cl}_{2}\right)$ production process, through electrolysis of sodium chloride and potassium chloride solutions respectively. In the future their respective roles may be reversed, with hydroxides being the most valuable outputs should DACCS reach such significant deployment.

According to the APS report ${ }^{6}$, there is a loss of $\mathrm{NaOH}$ solution during each capture cycle, as it remains partly entrained in the $\mathrm{CO}_{2}$-depleted air leaving the absorber. Considering the detailed mass balance provided by Baciocchi ${ }^{18}$, the make-up rate of sorbents is between 0.17 and 0.29 tonne per each tonne of $\mathrm{CO}_{2}$ captured, according to the different plant designs proposed. Note that this reference has been taken as a worst-case scenario for such technology. Currently the market for $\mathrm{Cl}_{2}$ is about $76.8 \mathrm{Mt} /$ year ${ }^{44}$, which would allow about $300-500$ $\mathrm{MtCO}_{2}$ being captured using $D A C 1$ plants. Therefore, the decision to limit DACCS maximum capacity to 3 and $30 \mathrm{GtCO}_{2} /$ year means scaling the current hydroxide market by a factor of 10 and 100 respectively. As a comparison, the current market for $\mathrm{KOH}$ and $\mathrm{NaOH}$ are about 0.8 and $80 \mathrm{Mt} /$ year, respectively. Finally, it must be noted that chlorine gas would be the main byproduct of hydroxide production raising concerns about its handling, since it is a highly poisonous gas and a potential ingredient in chemical warfare.

When moving to amine-based adsorbents, it becomes much more difficult to investigate their production and the need for sorbent replacement during the capture process as very few technical details are available in the literature. Therefore, we analyze the production process of polyethanolamines (mainly MEA, monoethanolamine) which are generally employed to capture $\mathrm{CO}_{2}$ from power plants, through post-combustion CCS processes. In this case, the synthesis starts from ammonia and ethylene oxide, requiring about 3.2 and 0.64 tonnes respectively per each tonne of MEA produced ${ }^{47}$. Both of them come from fossil fuel precursors, mainly oil and natural gas, although ethylene can also be made from biomass. It is an endothermic process, so no heat input is required to sustain the reaction, beside the energy costs for running the production plant itself, which can be neglected. There is no robust information about the replacement rate for amine-based adsorbents in $D A C 2$ plants, but it is likely to be considerable given the degradation of amine materials due to oxidation and steam exposure ${ }^{48}$. As a conservative approach, we consider a similar make-up rate to hydroxide solutions, resulting in 15 to $26 \mathrm{Gt} /$ year of ammonia (current market: $177 \mathrm{Mt} / \mathrm{year}^{45}$ ) and 3 to $5 \mathrm{Gt} /$ year of ethylene oxide (current market: 35 $\mathrm{Mt} /$ year $\left.^{46}\right)$.

All these values are summarized in Supplementary Table 3.

\section{Data availability}

The data that support the findings of this study are available from the authors on request.

Received: 4 March 2019 Accepted: 4 June 2019

Published online: 22 July 2019

\section{References}

1. Intergovernmental Panel on Climate Change (IPCC). Global warming of $1.5^{\circ}$ C. An IPCC Special Report on the impacts of global warming of $1.5^{\circ} \mathrm{C}$ above pre-industrial levels and related global greenhouse gas emission pathways, in the 
context of strengthening the global response to the threat of climate change, sustainable development, and efforts to eradicate poverty. (2018) (In Press).

2. Le Quéré, C. et al. Global carbon budget 2017. Earth Syst. Sci. Data 10, 405-448 (2018).

3. Intergovernmental Panel on Climate Change (IPCC). Climate Change 2014: Synthesis Report. Contribution of Working Groups I, II and III to the Fifth Assessment Report of the Intergovernmental Panel on Climate Change IPCC (Geneva, 2014)

4. Smith, L. J. \& Torn, M. S. Ecological limits to terrestrial biological carbon dioxide removal. Clim. Change 118, 89-103 (2013).

5. Smith, P. et al. Biophysical and economic limits to negative $\mathrm{CO}_{2}$ emissions. Nat. Clim. Change 6, 42-50 (2016).

6. Socolow, R. et al. Direct air capture of $\mathrm{CO}_{2}$ with chemicals. a technology assessment for the APS panel on public affairs. Tech. Rep. (2011).

7. Broehm, M., Strefler, J. \& Bauer, N. Techno-economic review of direct air capture systems for large scale mitigation of atmospheric $\mathrm{CO}_{2}$. https://ssrn. com/abstract $=2665702$ (2015).

8. Chen, C. \& Tavoni, M. Direct air capture of $\mathrm{CO}_{2}$ and climate stabilization: a model based assessment. Clim. Change 118, 59-72 (2013).

9. Marcucci, A., Kypreos, S. \& Panos, E. The road to achieving the long-term Paris targets: energy transition and the role of direct air capture. Clim. Change 144, 181-193 (2017).

10. Strefler, J. et al. Between scylla and charybdis: delayed mitigation narrows the passage between large-scale CDR and high costs. Environ. Res. Lett. 13, 4 (2018).

11. Carbon Engineering website. http://carbonengineering.com [Online, accessed 10-Dec-2018].

12. Climeworks website. http://www.climeworks.com [Online, accessed 10-Dec2018].

13. Global Thermostat website. Available at: https://globalthermostat.com/ [Online, accessed 10-Dec-2018].

14. Keith, D. W., Ha-Duong, M. \& Stolaroff, J. K. Climate strategy with $\mathrm{CO}_{2}$ capture from the air. Clim. Change 74, 17-45 (2006).

15. Nemet, G. F. et al. A negative emissions-part 3: innovation and upscaling Environ. Res. Lett. 13, 063003 (2018).

16. Fuss, S., Reuter, W. H., Szolgayová, J. \& Obersteiner, M. Optimal mitigation strategies with negative emission technologies and carbon sinks under uncertainty. Clim. Change 118, 73-87 (2013).

17. Keith, D. W., Holmes, G., Angelo, D. S. \& Heidel, K. A process for capturing $\mathrm{CO}_{2}$ from the atmosphere. Joule 2, 1-22 (2018).

18. Baciocchi, R., Storti, G. \& Mazzotti, M. Process design and energy requirements for the capture of carbon dioxide from air. Chem. Eng. Process. 45, 1047-1058 (2006).

19. Mazzotti, M., Baciocchi, R., Desmond, M. J. \& Socolow, R. H. Direct air capture of $\mathrm{CO}_{2}$ with chemicals: optimization of a two-loop hydroxide carbonate system using a countercurrent air-liquid contactor. Clim. Change 118, 119-135 (2013).

20. Holmes, G. \& Keith, D. W. An air-liquid contactor for large-scale capture of $\mathrm{CO}_{2}$ from air. Philos. Trans. R. Soc. A 370, 4380-4403 (2012).

21. Goeppert, A., Czaun, M., Surya Prakash, G. K. \& Olah, G. A. Air as the renewable carbon source of the future: an overview of $\mathrm{CO}_{2}$ capture from the atmosphere. Energy Environ. Sci. 5, 7833 (2012).

22. Gebald, C., Wurzbacher, J. A., Tingaut, P. \& Zimmermann, T. Amine-based nanofibrillated cellulose as adsorbent for $\mathrm{CO}_{2}$ capture from air. Environ. Sci. Technol. 45, 9101-9108 (2011).

23. Eisenberg, P. \& Chichilnisky, G. System and method for removing carbon dioxide from an atmosphere and global thermostat using the same. US Patent Application 12/124,864 (2008).

24. Lackner, K. S. Capture of carbon dioxide from ambient air. Eur. Phys. J.: Spec. Top. 176, 93-106 (2009).

25. Sanz-Pérez, E. S., Murdock, C. R., Didas, S. A. \& Jones, C. W. Direct capture of $\mathrm{CO}_{2}$ from ambient air. Chem. Rev. 116, 11840-11876 (2016).

26. Veselovskaya, J. V. et al. Direct $\mathrm{CO}_{2}$ capture from ambient air using $\mathrm{K}_{2} \mathrm{CO}_{3} /$ $\mathrm{Al}_{2} \mathrm{O}_{3}$ composite sorbent. Int. J. Greenh. Gas. Control 17, 332-340 (2013).

27. Wilcox, J. et al. Assessment of reasonable opportunities for direct air capture. Environ. Res. Lett. 12, 065001 (2017)

28. Iyer, G. et al. Diffusion of low-carbon technologies and the feasibility of longterm climate targets. Technol. Forecast. Soc. Change 90, 103-118 (2015).

29. Tavoni, M. \& Socolow, R. Modeling meets science and technology: an introduction to a special issue on negative emissions. Clim. Change 118, 1-14 (2013).

30. Lenton, T. M. Chapter 3. The Global Potential for Carbon Dioxide Removal. (The Royal Society of Chemistry, London, 2014).

31. Solar Power Europe. Global Market Outlook 2018-2022 (2018).

32. International Renewable Energy Agency (IRENA). Global Energy Transformation: A roadmap to 2050. www.irena.org/publications (IRENA, Abu Dhabi, 2018).

33. Wilson, C. Up-scaling, formative phases, and learning in the historical diffusion of energy technologies. Energy Policy 50, 81-94 (2012).
34. Wilson, C. Meta-analysis of unit and industry level scaling dynamics in energy technologies and climate change mitigation scenarios. IIASA Interim Report. IR-09-029 (IIASA, Laxenburg, 2009).

35. British Petroleum (BP). Statistical review of world energy 2018. http://www. bp.com/statisticalreview (2018).

36. Van Vuuren, D. P. et al. Alternative pathways to the $1.5^{\circ} \mathrm{C}$ target reduce the need for negative emission technologies. Nat. Clim. Change 8, 391-397 (2018).

37. Honegger, M. \& Reiner, D. The political economy of negative emissions technologies: consequences for international policy design. Clim. Policy 18, 306-321 (2018).

38. Carbonbrief webarticle. https://www.carbonbrief.org/swiss-company-hopingcapture-1-global-co2-emissions-2025 (2017).

39. Organisation internationale des constructeurs d'automobiles (Oica). http:// oica.net/category/production-statistics/ (2017).

40. McLaren, D. A comparative global assessment of potential negative emissions technologies. Process Saf. Environ. Prot. 90, 489-500 (2012).

41. Jackson, R. B. et al. Focus on negative emissions. Environ. Res. Lett. 12, 110201 (2017).

42. Fuss, S. et al. Negative emissions-part 2: costs, potentials and side effects. Environ. Res. Lett. 13, 063002 (2018).

43. IEA (2018), World Energy Balances 2018, OECD Publishing, Paris, https:// doi.org/10.1787/world_energy_bal-2018-en

44. Brinkmann, T. Best Available Techniques (BAT) Reference Document for the Production of Chlor-alkali. Tech. Rep. (2014).

45. United States Geological Survey. Mineral commodity summaries 2018. (2018)

46. Research In China. Global and China Ethylene Oxide (EO) Industry Report, 2017-2021. Tech. Rep. (2017).

47. Zahedi, G., Amraei, S. \& Biglari, M. Simulation and optimization of ethanol amine production plant. Korean J. Chem. Eng. 26, 1504-1511 (2009).

48. Didas, S. A., Choi, S., Chaikittisilp, W. \& Jones, C. W. Amine-oxide hybrid materials for CO2 capture from ambient air. Acc. Chem. Res. 48, 2680-2687 (2015).

49. Gruber, N. et al. Oceanic sources, sinks, and transport of atmospheric $\mathrm{CO}_{2}$. Glob. Biogeochem. Cycles 23, GB1005 (2009).

50. Cao, L. \& Caldeira, K. Atmospheric carbon dioxide removal: long-term consequences and commitment. Environ. Res. Lett. 5, 024011 (2010).

51. Vichi, M., Navarra, A. \& Fogli, P. G. Adjustment of the natural oceancarbon cycle to negative emission rates. Clim. Change 118, 105-118 (2013).

52. Jones, C. D. et al. Simulating the Earth system response to negative emissions. Environ. Res. Lett. 11, 095012 (2016)

53. Riahi, K. et al. Locked into Copenhagen pledges-implications of short term emission targets for the cost and feasibility of long term climate goals. Technol. Forecast. Soc. Change 90, 8-23 (2015).

54. Matthews, H. D., Zickfeld, K., Knutti, R. \& Allen, M. R. Focus on cumulative emissions, global carbon budgets and the implications for climate mitigation targets. Environ. Res. Lett. 13, 010201 (2018).

55. McLaren, D., Jarvis, A. Quantifying the potential scale of mitigation deterrence from greenhouse gas removal techniques, AMDEG Working Paper 2 (2018). http://wp.lancs.ac.uk/amdeg/files/2018/12/AMDEG-WorkingPaper-2-Quantifying-MD-GGR.pdf

56. Larkin, A. et al. What if negative emission technologies fail at scale? Implications of the Paris Agreement for big emitting nations. Clim. Policy 18, 690-714 (2018)

57. Grubler, A. et al. A low energy demand scenario for meeting the $1.5^{\circ} \mathrm{C}$ target and sustainable development goals without negative emission technologies. Nat. Energy 3, 515-527 (2018).

58. Markusson, N. O., McLaren, D. P. \& Tyfield, D. P. Towards a cultural political economy of mitigation deterrence by negative emissions technologies (NETs). Glob. Sustain. 1, e10 (2018).

59. Lenzi, D. The ethics of negative emissions. Glob. Sustain. 1, e7 (2018).

60. Bednar, J., Obersteiner, M. \& Wagner, F. On the financial viability of negative emissions. Nat. Coomunications 10, 1783 (2019).

61. Loulou, R. \& Labriet, M. ETSAP-TIAM: the TIMES integrated assessment model part I: model structure. Comput. Manag. Sci. 5, 7-40 (2008).

62. Loulou, R. ETSAP-TIAM: the TIMES integrated assessment model. Part II: mathematical formulation. Comput. Manag. Sci. 5, 41-66 (2008).

63. Bosetti, V., Carraro, C., Galeotti, M., Massetti, E. \& Tavoni, M. WITCH: a world induced technical change hybrid model. Energy J. 27, 13-37 (2006).

64. Bosetti, V., De Cian, E., Sgobbi, A. \& Tavoni, M. The 2008 Witch model: new model features and baseline. FEEM Working Paper. (Fondazione Eni Enrico Mattei, Milano, 2009).

65. Rogelj, J. et al. Paris agreement climate proposals need a boost to keep warming well below $2{ }^{\circ} \mathrm{C}$. Nature 534, 631-639 (2016).

66. Rogelj, J. et al. Scenarios towards limiting global mean temperature increase below $1.5^{\circ} \mathrm{C}$. Nat. Clim. Change 8, 325-332 (2018)

67. Goeppert, A. et al. Easily regenerable solid adsorbents based on polyamines for carbon dioxide capture from the air. ChemSusChem 7 5, 1386-1397 (2014). 
68. Ishimoto, Y. et al. Putting costs of direct air capture in context. FCEA Working Paper Series (2017). https://ssrn.com/abstract=2982422

69. Breyer, C., Fasihi, M. \& Aghahosseini, A. Carbon dioxide direct air capture for effective climate change mitigation based on renewable electricity: a new type of energy system sector coupling. Mitig. Adapt. Strateg. Glob. Change1-23, 24, (2019).

70. Kintisch, E. MIT technology review: can sucking $\mathrm{CO}_{2}$ out of the atmosphere really work? http://globalthermostat.com/wp-content/uploads/2014/10/MITTechnology-Review-Global-Thermostat.pdf (2014)

71. Farmer, J. D. \& Lafond, F. How predictable is technological progress? Res. Policy 45, 647-665 (2016).

72. McKenna, R. C. \& Norman, J. B. Spatial modelling of industrial heat loads and recovery potentials in the UK. Energy Policy 38, 5878-5891 (2010).

73. Khamis, I., Koshy, T. \& Kavvadias, K. C. Opportunity for Cogeneration in Nuclear Power Plants. In Proc. The 2013 World Congress on Advances in Nano, Biomechanics, Robotics, and Energy Research (2013).

74. Norwood, Z. \& Kammen, D. Life cycle analysis of distributed concentrating solar combined heat and power: Economics, global warming potential and water. Environ. Res. Lett. 7, 044016 (2012).

75. Creutzig, F. et al. Bioenergy and climate change mitigation: an assessment. https://doi.org/10.1111/gcbb.12205 (2015).

76. Stolaroff, J. K., Keith, D. W. \& Lowry, G. V. Carbon dioxide capture from atmospheric air using sodium hydroxide spray. Environ. Sci. Technol. 42, 2728-2735 (2008).

77. National Academies of Sciences. Engineering and Medicine. Negative Emissions Technologies and Reliable Sequestration: A Research Agenda. (The National Academies Press, Washington, DC 2018).

\section{Acknowledgements}

J.G. is supported by a research grant from Science Foundation Ireland (SFI) and the National Natural Science Foundation of China (NSFC) under the SFI-NSFC Partnership Programme Grant Number 17/NSFC/5181. We want to thank the Integrated Assessment Modeling Consortium (IAMC) for the constructive discussion and the feedback provided during the 11th IAMC Meeting in Seville, during which a first draft of this research has been presented.

\section{Author contributions}

G.R. and M.T. conceived the study. G.R., M.T., A.G., and L.D. designed the scenarios, which were developed by G.R. and L.D. J.G., A.C.K., A.H. contributed tools and analysis methods. G.R. wrote a first draft of the paper. All authors provided feedback throughout the work and contributed to the writing of the article.

\section{Additional information}

Supplementary Information accompanies this paper at https://doi.org/10.1038/s41467019-10842-5.

Competing interests: The authors declare no competing interests.

Reprints and permission information is available online at http://npg.nature.com/ reprintsandpermissions/

Peer review information: Nature Communications thanks Duncan McLaren and the other anonymous reviewer(s) for their contribution to the peer review of this work.

Publisher's note: Springer Nature remains neutral with regard to jurisdictional claims in published maps and institutional affiliations.

(c) (i) Open Access This article is licensed under a Creative Commons Attribution 4.0 International License, which permits use, sharing, adaptation, distribution and reproduction in any medium or format, as long as you give appropriate credit to the original author(s) and the source, provide a link to the Creative Commons license, and indicate if changes were made. The images or other third party material in this article are included in the article's Creative Commons license, unless indicated otherwise in a credit line to the material. If material is not included in the article's Creative Commons license and your intended use is not permitted by statutory regulation or exceeds the permitted use, you will need to obtain permission directly from the copyright holder. To view a copy of this license, visit http://creativecommons.org/ licenses/by/4.0/.

(C) The Author(s) 2019 